\title{
Urapidil, compared to nitroglycerin, has better clinical safety in the treatment of hypertensive patients with acute heart failure: a meta-analysis
}

This article was published in the following Dove Medical Press journal:

Drug Design, Development and Therapy

\author{
Jiaxiao Shi ${ }^{1,2, *}$ \\ Yulin $\mathrm{Li}^{1,2, *}$ \\ Cong Xing ${ }^{1,2, *}$ \\ Peng Peng ${ }^{1,2}$ \\ Hongyu Shi, ${ }^{1,2}$ \\ Han Ding ${ }^{1,2}$ \\ Pengyuan Zheng ${ }^{1,2}$ \\ Guangzhi Ning ${ }^{1,2}$ \\ Shiqing Feng ${ }^{1,2}$ \\ 'Department of Orthopaedics, Tianjin \\ Medical University General Hospital, \\ Heping District, Tianjin 300052, \\ PR China; ${ }^{2}$ Tianjin Neurological \\ Institute, Key Laboratory of Post- \\ Neuroinjury Neuro-repair and \\ Regeneration in Central Nervous \\ System, Ministry of Education and \\ Tianjin City, Heping District, Tianjin \\ 300052, PR China \\ *These authors contributed equally \\ to this work
}

\begin{abstract}
Objectives: The application of urapidil for treating hypertensive patients with acute heart failure in the emergency department remains controversial. Our objective was to organize the relevant articles and assess the clinical indexes between urapidil and nitroglycerin.

Materials and methods: PubMed, EMBASE, the Cochrane Library and China National Knowledge Infrastructure were searched for randomized studies that compared urapidil treatment with nitroglycerin treatment for hypertensive patients with acute heart failure. The risk ratio, with 95\% CI, was calculated by using a corresponding effects model, according to the value of $I^{2}$.

Results: Seven randomized controlled trials were identified, in order to compare the clinical indexes. On comparing the clinical indexes, the urapidil group was found to be better than the nitroglycerin group in regard to left ventricular ejection fraction, systolic blood pressure, $\mathrm{N}$-terminal prohormone of brain natriuretic peptide, left ventricular end-diastolic volume, cardiac index, ALT, AST and health complications $(P<0.05)$, but the indexes of creatinine were worse in the urapidil group. Furthermore, the two methods of treatment were comparable in diastolic blood pressure, left ventricular end-systolic volume, left ventricular end-systolic dimension, heart rate, fasting plasma glucose and total cholesterol levels $(P>0.05)$.

Conclusion: Based on the current evidence, urapidil treatment had better clinical safety features than the traditional pharmaceutical treatment with nitroglycerin. For those indicators with a small amount of data, a greater number of randomized, high-quality controlled trials should be conducted in order to further verify the findings, which could give researchers a more comprehensive evaluation of urapidil treatment.
\end{abstract}

Keywords: urapidil, nitroglycerin, acute heart failure, meta-analysis

\section{Introduction}

Chronic heart failure (CHF) is a common disease that is widespread throughout the world, with nearly 20 million people suffering from this disease. ${ }^{1}$ According to statistics, most patients with acute heart failure (AHF) have a history of $\mathrm{CHF},{ }^{2}$ which occurs in both developing and developed countries. ${ }^{3,4}$ In addition, every occurrence of AHF affects other organ systems outside of the heart and accelerates the development of chronic diseases, thus leading to further increases in mortality due to AHF. ${ }^{5}$ In the population that suffers from AHF, we find that elderly patients with hypertension account for a large proportion, although treatment strategies are lacking. ${ }^{6}$ Various types of drugs and treatment methods are constantly being updated for the treatment of different types of heart failure; consequently, deaths due to CHF have been reduced, but the mortality rate of AHF is still high. ${ }^{7}$ In the USA, most of these patients are treated in the emergency department, which results in heart failure diseases being common
Correspondence: Shiqing Feng;

Guangzhi Ning

Department of Orthopaedics, Tianjin Medical University General Hospital, No 154 Anshan Road, Heping District, Tianjin 300052, PR China

$\mathrm{Tel}+8602288366139$

Fax +8602288366139

Email sqfeng@tmu.edu.cn; ningguangzhi@foxmail.com

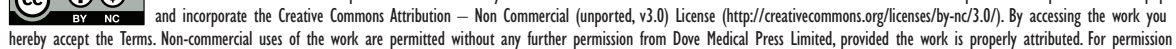
for commercial use of this work, please see paragraphs 4.2 and 5 of our Terms (https://www.dovepress.com/terms.php). 
and expensive diseases that represent a heavy burden to the society. ${ }^{8,9}$

The preferred treatment of hypertensive patients who have AHF, especially those who have significantly high blood pressure, severe distress and hypertension with AHF, usually involves the use of vasodilators, ${ }^{10,11}$ which can be found in the guide. ${ }^{12,13}$ The most commonly used vasodilators are nitroglycerin and other nitrates. This kind of drug can reduce heart filling pressure and SBP by reducing systemic vascular resistance. ${ }^{10,14}$ However, nitroglycerin has some side effects such as headache, flushing and reflex tachycardia. ${ }^{15}$

Urapidil acts as an antihypertensive drug and works by binding to both the $\alpha 1$-adrenoceptor in the peripheral vascular system and the serotonin (1A) receptors of 5-hydroxytryptamine $\left(5-\mathrm{HT}_{1 \mathrm{~A}}\right)$ receptor in the central nervous system. ${ }^{16,17}$ By inducing peripheral arteriovenous and pulmonary artery dilation, blood pressure gradually stabilizes. ${ }^{18,19}$ The effective and safe usage of urapidil was confirmed in studies focusing on hypertensive emergency patients, and the most suitable, applicable patients were the elderly. ${ }^{20,21}$

In this study, we evaluated the efficacy and safety of urapidil compared with the efficacy and safety of nitroglycerin in the treatment of elderly patients with AHF.

\section{Materials and methods}

The present study was completed according to the PRISMA statement (Checklist S1 in Supplementary material).

\section{Search strategy}

Two investigators reviewed literature based on the patient/ population intervention comparison outcome model principles. $^{22}$ The keywords used in these searches were "urapidil" and "heart failure", which were searched in the drop-down menu (All Fields) of the advanced search bars in the PubMed (US National Institute of Health's National Library of Medicine), EMBASE (a highly versatile, multipurpose and up-to-date biomedical database), The Cochrane Library (a database that brings together research on the effectiveness of health care treatments and interventions) and China National Knowledge Infrastructure, and these terms were connected by using the search term "AND". The initial time periods and languages of the searches were not limited, they just ruled the deadline to June 17, 2018. As searches under the guideline "Title/Abstract" resulted in the loss of relevant documents, the "All Fields" guideline was utilized. Finally, the eligible articles were chosen by the selection criteria. For disagreements on the selection of the studies, we submitted them to more experienced individuals to decide on the selection.

\section{Selection criteria}

1. Participants. The inclusion criteria for the study were as follows: patients who satisfied the standard diagnostic criteria for hypertension (China Guidelines [2010]) and the standard diagnostic criteria for AHF (New York Heart Association [NYHA] II, III and IV). ${ }^{23}$ Patients' ages were not limited by the study. The exclusion criteria were as follows: SBP $\leq 100 \mathrm{mmHg}$, cardiogenic shock, a contraindication of venous vasodilators, severe valve stenosis, hypertrophic obstructive cardiomyopathy, restrictive pericarditis, severe liver and kidney insufficiency or a tendency for bleeding, severe infection or autoimmune disease, a malignant tumor, a cerebrovascular accident or contraindication of related drugs, severe chronic wheezing bronchitis or acute pulmonary disease and allergies to drugs that were used in the institute.

2. Intervention and comparison. The patients who received the urapidil treatment were represented as the intervention group, and the patients who received nitroglycerin were represented as the control group. Patients who had received other types of antihypertensive treatment were excluded.

3. Outcomes. The clinical indexes containing DBP, SBP, heart rate (HR), N-terminal prohormone of brain natriuretic peptide (NT-proBNP), left ventricular ejection fraction (LVEF), left ventricular end-diastolic volume (LVEDV), left ventricular end-systolic volume (LVESV), left ventricular end-systolic dimension (LVESD), cardiac index, ALT, AST, LDL, creatinine levels, fasting plasma glucose levels, total cholesterol levels and disease complications were included as the outcomes of the study.

4. Study design. Randomized controlled trials (RCTs) that compared the use of urapidil with the use of nitroglycerin were considered as studies qualified for the analysis.

\section{Quality assessment}

We divided selection, performance, detection, attrition, reporting and other biases into three degrees of risk and assessed the quality of the RCTs by using the Cochrane Handbook.

\section{Data extraction}

We extracted the data on first author, publication time, country, study design, number of patients, mean ages, percentages of sex and interventions. Any disagreements with the selected studies were decided by the other individuals who were previously mentioned. 


\section{Data analysis and statistical methods}

Review Manager (version 5.3) was used to analyze the data. A risk ratio was used to calculate the dichotomous results, and the mean difference (MD) and standard mean difference were used to calculate both similar and differing evaluation indictor data of the dichotomous results, respectively. Furthermore, we used $I^{2}$ values to assess the heterogeneity among the articles. If $I^{2}>50$, we used the random-effect model; conversely, if $I^{2}<50$, we used the fixed-effect model.

\section{Results}

\section{Search results}

Through our query method, we searched a total of 378 articles and removed 44 identical articles by checking for duplicated articles. According to the understanding of the title and abstract, the investigators eliminated 299 articles. Finally, we selected seven articles after excluding similar articles by reading and analyzing the full text. The entire document screening process is represented in Figure 1.

\section{Risk of bias assessment}

In these incorporated studies, all studies were RCTs, and the methodological quality of each study was evaluated according to the Cochrane Collaboration's tool. Only two RCTs were considered to be low risk, whereas the remainder were not considered to be of a better quality, due to an uncertainty bias. In these studies, the biases mainly existed in regard to allocation concealment, binding of participants and other biases. The detailed contents are shown in Figure 2A and B.

\section{Study characteristics}

Of the seven included articles, five studies were single-center studies and two studies were multicenter studies. For the two multicenter studies, we conducted a textual research

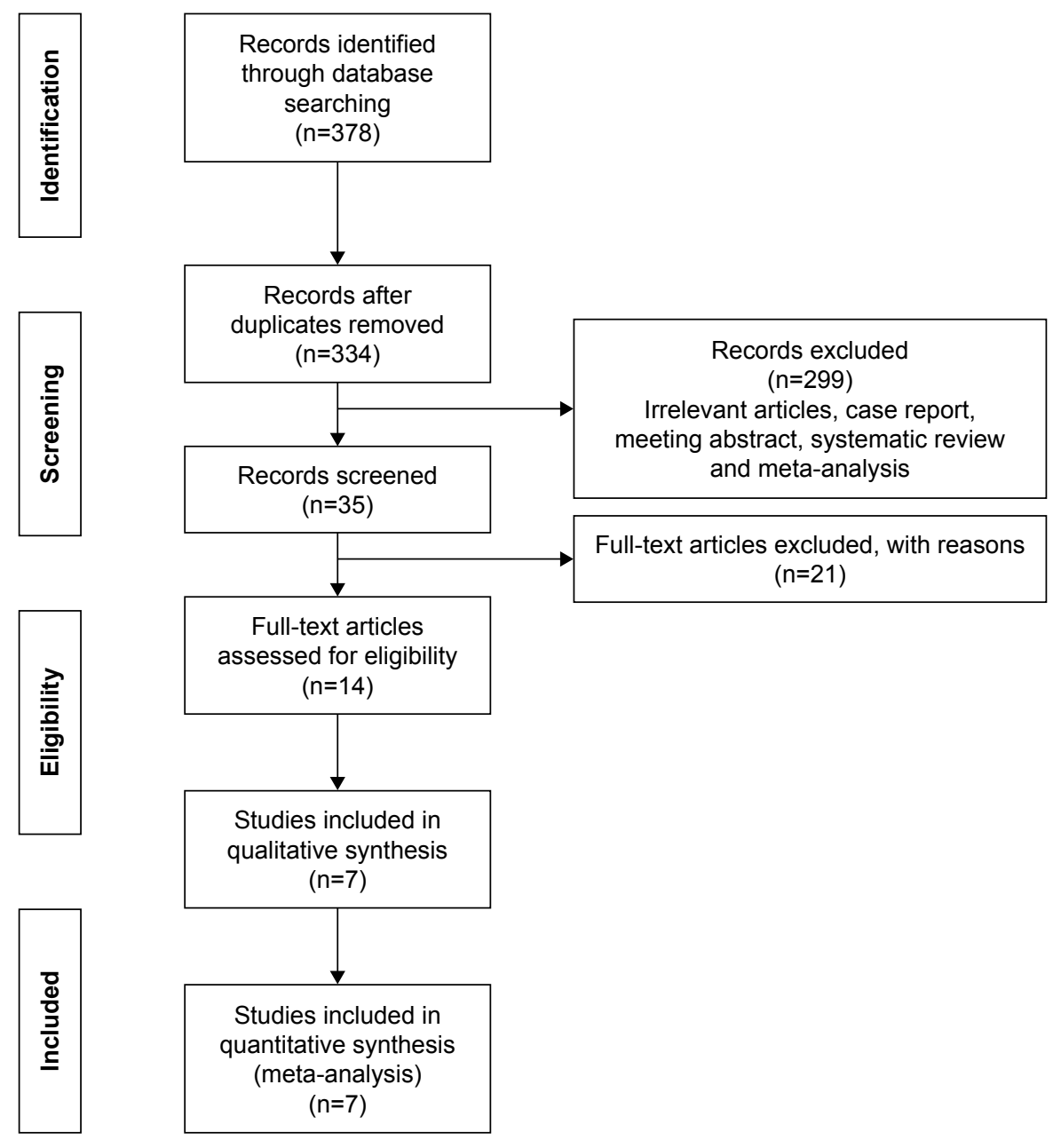

Figure I Flowchart of the study selection process. 
A

Random sequence generation (selection bias)

Allocation concealment (selection bias)

Blinding of participants and personnel (performance bias)

Blinding of outcome assessment (detection bias)

Incomplete outcome data (attrition bias)

Selective reporting (reporting bias)

Other bias

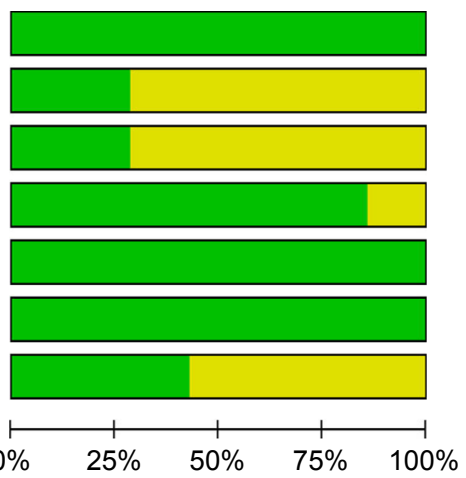

Low risk of bias $\square$ Unclear risk of bias $\square$ High risk of bias

B
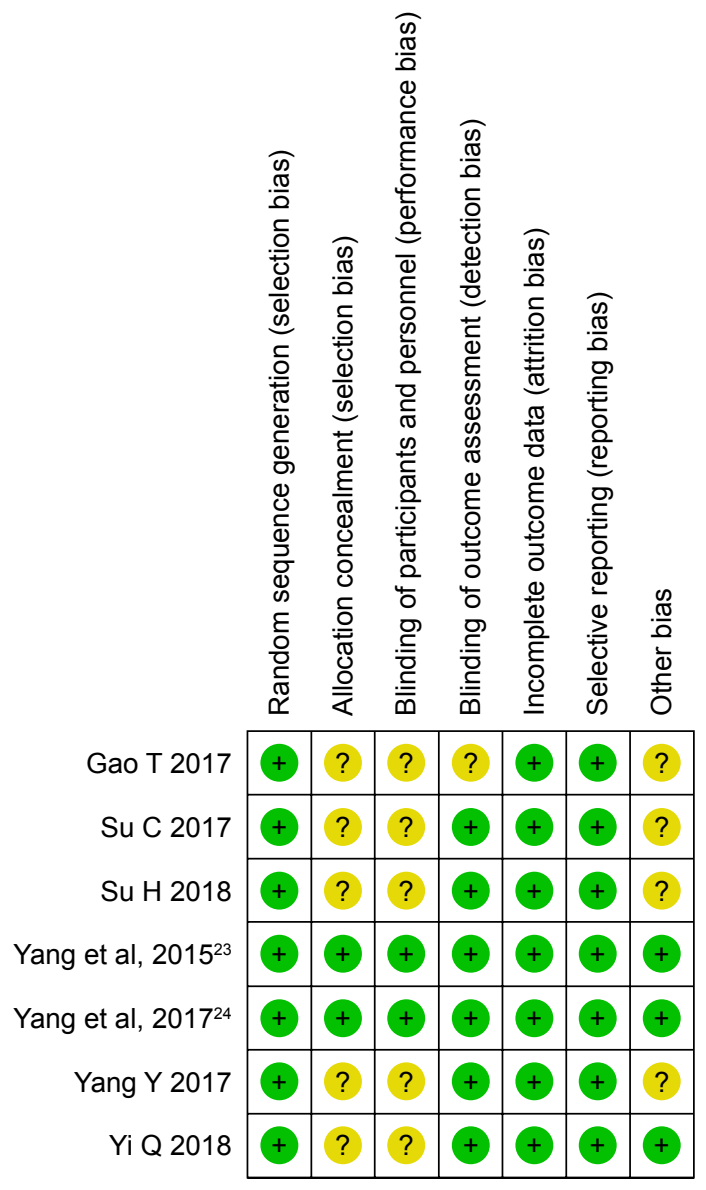

Figure 2 (A) Risk of bias graph. (B) Risk of bias summary.

and judgment in order to ensure that there were no repeated patients between the two studies. Nearly every article offered the general characteristics of the study populations. In all of the articles, the patients' conditions were evaluated by using the standard diagnostic criteria for hypertension (China Guidelines [2010]) and acute HF (NYHA II, III and IV). Finally, 1,028 patients were included in our study. Among them, 512 patients were treated with urapidil and 516 patients received nitroglycerin. The characteristics of these documents are presented in Table 1.

\section{Outcomes of meta-analysis} DBP, SBP, LVEF, LVESV and LVESD after 2 days of treatment

Three reports provided data $(\mathrm{n}=462)$ on DBP, SBP, LVEF, LVESV and LVESD. A random-effect model was used in 


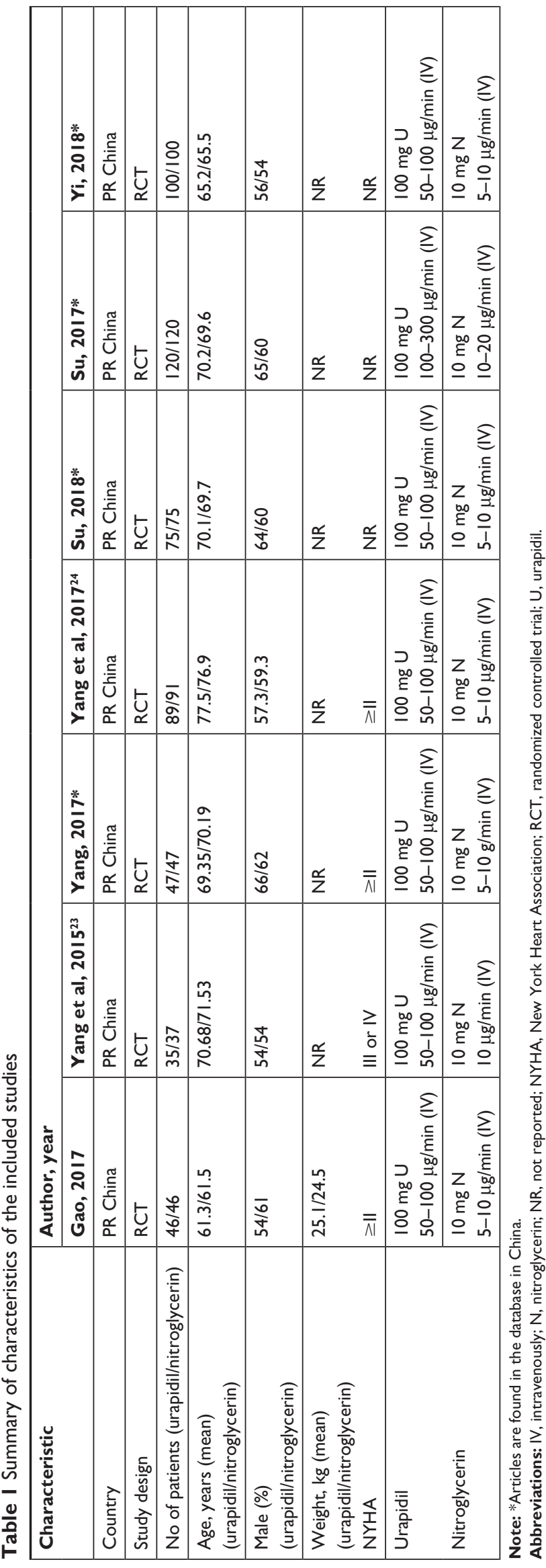

the evaluation of DBP, SBP, LVESV and LVESD, due to the obvious heterogeneity that existed among the studies (DBP: $I^{2}=97 \%, P \leq 0.00001$; SBP: $I^{2}=97 \%, P \leq 0.00001$; LVESV: $I^{2}=88 \%, P=0.003$; LVESD: $\left.I^{2}=83 \%, P=0.01\right)$. A fixed-effect model was used for the analysis of LVEF and no significant heterogeneity was found (LVEF: $I^{2}=0 \%, P=0.99$ ). The effect of hypotension on DBP, SBP, LVESV and LVESD in the urapidil treatment group was not lower than that in the nitroglycerin group (DBP: two studies, 312 participants, MD: -3.72 , 95\% CI: $-15.75,8.32, P=0.54$; SBP: two studies, 312 participants, MD: $-1.46,95 \%$ CI: $-16.12,13.20, P=0.85$; LVESV: two studies, 390 participants, MD: 0.35, 95\% CI: $-24.49,25.19$, $P=0.98$; LVESD: two studies, 390 participants, MD: -0.36 , $95 \%$ CI: $-0.86,0.15, P=0.17$ ). The effect of hypotension on LVEF in the urapidil group was better than that in the nitroglycerin group (LVEF: two studies, 390 participants, MD: 4.25, 95\% CI: 1.86, 6.64, $P=0.0005$; Figure 3).

\section{DBP, SBP, HR, CI, NT-proBNP, LVEF and LVEDV after 7 days of treatment}

There were five reports that provided data $(\mathrm{n}=638)$ for $\mathrm{DBP}$, SBP, HR, CI, NT-proBNP, LVEF and LVEDV. Randomeffect models were used for the analysis of DBP, SBP, NTproBNP, LVEF and LVEDV, which had a higher degree of heterogeneity (DBP: $I^{2}=69 \%, P=0.04$; SBP: $I^{2}=93 \%$, $P \leq 0.00001$; NT-proBNP: $I^{2}=98 \%, P \leq 0.00001$; LVEF: $I^{2}=78 \%, P=0.001$; LVEDV: $I^{2}=67 \%, P=0.03$ ). Fixed-effect models were used for the analysis of HR and CI, and they exhibited a small degree of heterogeneity (HR: $I^{2}=17 \%$, $P=0.30$; CI: $I^{2}=10 \%, P=0.33$ ). The effect of hypotension on DBP and HR in the urapidil group was not lower than that in the nitroglycerin group (DBP: three studies, 258 participants, MD: $-2.60,95 \% \mathrm{CI}:-5.40,0.19, P=0.07$; HR: three studies, 258 participants, MD: $-0.77,95 \%$ CI: $-1.63,0.09$, $P=0.08$ ). The effect of hypotension on SBP, NT-proBNP, LVEF, LVEDV and CI in the urapidil group was better than that in the nitroglycerin group (SBP: four studies, 438 participants, MD: $-10.93,95 \% \mathrm{CI}:-16.66,-5.20, P=0.0002$; NT-proBNP: four studies, 438 participants, MD: -5.23 , 95\% CI: $-7.64,-2.82, P<0.0001$; LVEF: five studies, 638 participants, MD: 9.75, 95\% CI: 8.42, 11.09, $P<0.00001$; LVEDV: four studies, 544 participants, MD: $-17.36,95 \%$ CI: $-22.27,-12.45, P<0.00001$; CI: three studies, 364 participants, MD: 0.69, 95\% CI: 0.57, 0.80, $P<0.00001$; Figure 4).

\section{ALT and AST after 7 days of treatment}

Two reports reported the statuses of ALT and AST after medication treatments. We again used random-effect models, 


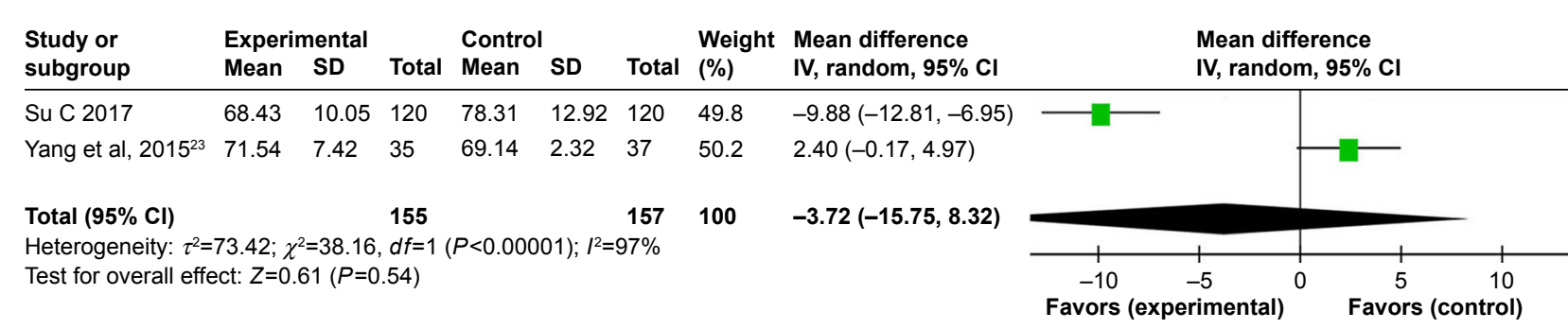

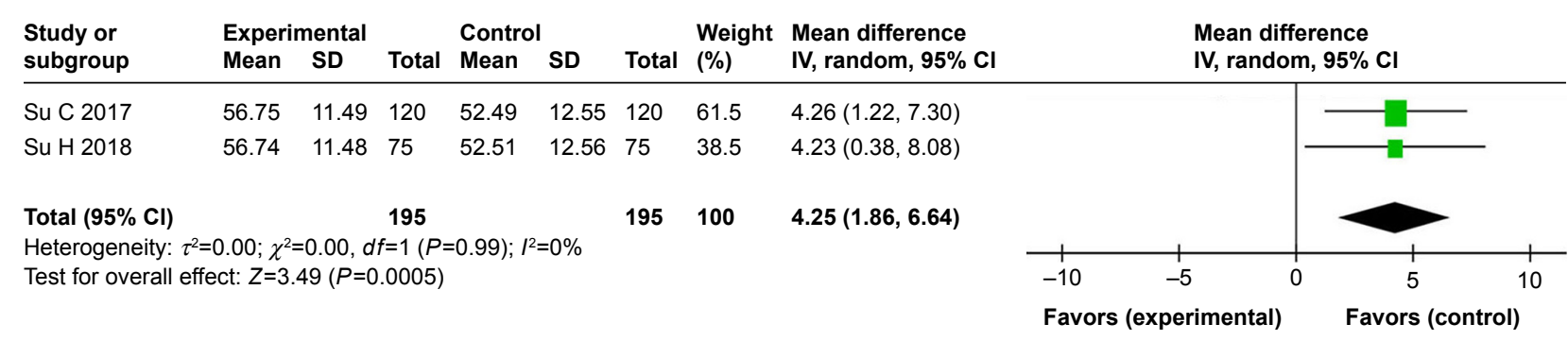

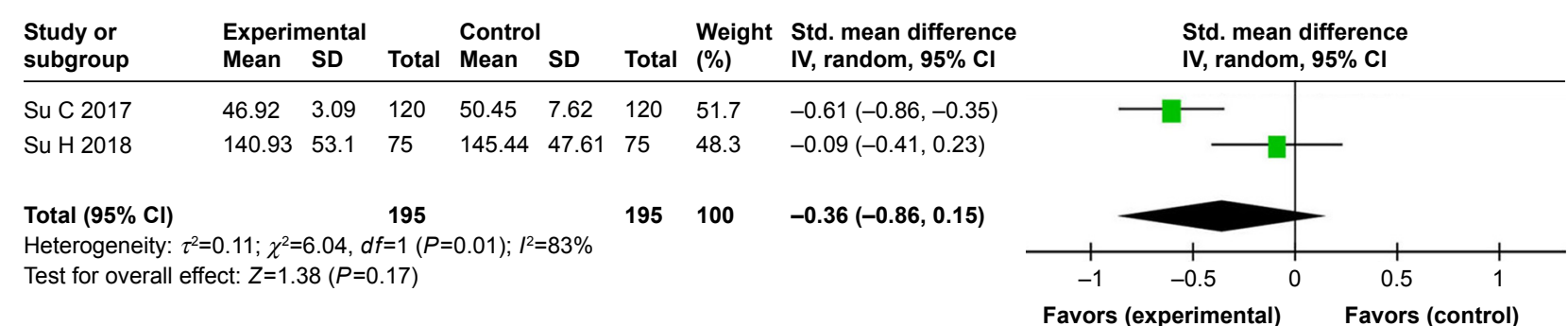

\begin{tabular}{|c|c|c|c|c|c|c|c|c|c|c|c|c|}
\hline $\begin{array}{l}\text { Study or } \\
\text { subgroup }\end{array}$ & \multicolumn{2}{|c|}{$\begin{array}{l}\text { Experimental } \\
\text { Mean SD }\end{array}$} & \multirow{2}{*}{$\begin{array}{l}\text { Total } \\
120\end{array}$} & \multirow{2}{*}{$\begin{array}{l}\text { Control } \\
\text { Mean }\end{array}$} & \multirow{2}{*}{$\begin{array}{l}\text { SD } \\
39.09\end{array}$} & \multirow{2}{*}{$\begin{array}{l}\text { Total } \\
120\end{array}$} & \multirow{2}{*}{$\begin{array}{l}\text { Weight } \\
\text { (\%) }\end{array}$} & \multirow{2}{*}{$\begin{array}{l}\begin{array}{l}\text { Mean difference } \\
\text { IV, random, } 95 \% \text { CI }\end{array} \\
12.69(2.19,23.19)\end{array}$} & \multicolumn{4}{|c|}{$\begin{array}{l}\text { Mean difference } \\
\text { IV, random, } 95 \% \mathrm{Cl}\end{array}$} \\
\hline Su C 2017 & 80.37 & 43.75 & & & & & & & & & - & \\
\hline Su H 2018 & 67.69 & 39.11 & 75 & 80.36 & 43.74 & 75 & 48.7 & $-12.67(-25.95,0.61)$ & & & & \\
\hline \multicolumn{3}{|l|}{ Total $(95 \% \mathrm{Cl})$} & 195 & & & 195 & 100 & $0.35(-24.49,25.19)$ & & & & \\
\hline \multicolumn{13}{|c|}{ Heterogeneity: $\tau^{2}=284.27 ; \chi^{2}=8.62, d f=1(P=0.003) ; I^{2}=88 \%$} \\
\hline \multirow{2}{*}{\multicolumn{9}{|c|}{ Test for overall effect: $Z=0.03(P=0.98)$}} & -50 & -25 & 25 & 50 \\
\hline & & & & & & & & & Favors & erim & Favors & trol) \\
\hline
\end{tabular}

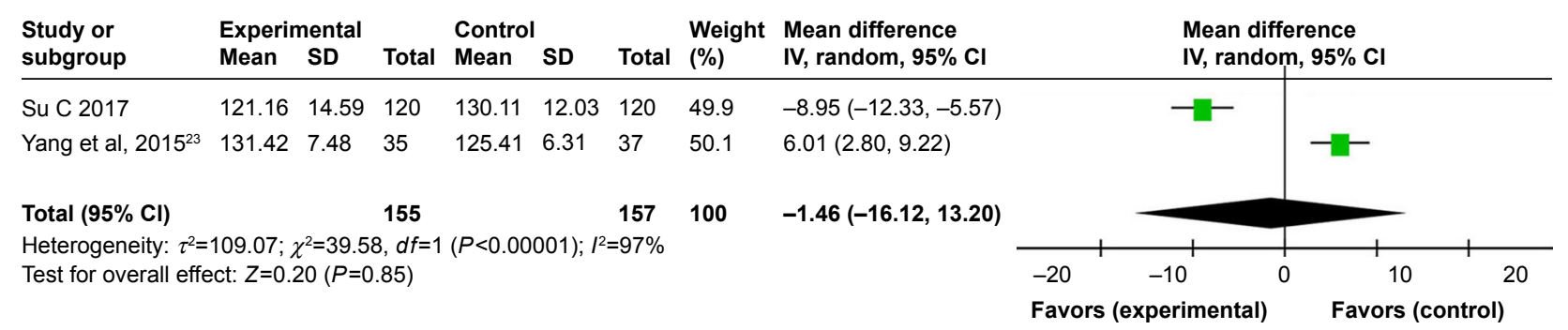

Figure 3 Forest plot diagram showing the DBP, SBP, LVEF, LVESV and LVESD.

Abbreviations: $d f$, degrees of freedom; IV, intravenously; LVEF, left ventricular ejection fraction; LVESD, left ventricular end-systolic dimension; LVESV, left ventricular end-systolic volume.

and a significant heterogeneity was not found for AST, but a significant heterogeneity was found for ALT (AST: $I^{2}=0 \%, P=0.33$; ALT: $\left.I^{2}=63 \%, P=0.10\right)$. The advantage of the urapidil group was demonstrated for both AST and ALT (AST: two studies, 252 participants, MD: $-2.45,95 \%$ CI: $-3.27,-1.63, P<0.00001$; ALT: two studies, 252 participants, MD: $-2.60,95 \% \mathrm{CI}:-4.86,-0.33, P=0.02$; Figure 5).

\section{Creatinine after 7 days of treatment}

Three studies, with a total of 346 patients, supported the index of creatinine. Random-effect models were used, and a highly significant heterogeneity was observed $\left(I^{2}=91 \%\right.$, $P<0.00001)$. The level of creatinine that occurred in the urapidil group was higher than that in the nitroglycerin group (MD: 6.50, 95\% CI: 1.63-11.36, $P=0.009$; Figure 6). 
Fasting plasma glucose after 7 days of treatment

The levels of fasting blood glucose were provided in three reports that included a total of 346 patients. Randomeffect models were used, and no heterogeneity was found $\left(I^{2}=0 \%, P=0.61\right)$. The level of fasting blood glucose in the experimental group was higher than that in the control group (MD: $-0.05,95 \% \mathrm{CI}:-0.44,0.33, P=0.79$ ). The subgroup of diabetic patients also exhibited the same results $\left(I^{2}=0 \%, P=0.42\right.$, MD: $-0.31,95 \%$ CI: $-1.24,0.63, P=0.52$; Figures 7 and 8).

\section{Total cholesterol}

Two articles, with a total of 166 patients, provided outcomes of total cholesterol levels. Random-effect models were used, and an obvious and significant heterogeneity was found $\left(I^{2}=98 \%, P<0.00001\right)$. The results showed that total cholesterol levels in the urapidil group were higher than those in the nitroglycerin group (MD: $-0.02,95 \% \mathrm{CI}:-1.84,1.81$, $P=0.99)$. The subgroup of diabetic patients exhibited the opposite result ( $I^{2}=0 \%, P=0.77$, MD: $0.82,95 \%$ CI: 0.45 , 1.20, $P<0.001$; Figures 9 and 10).

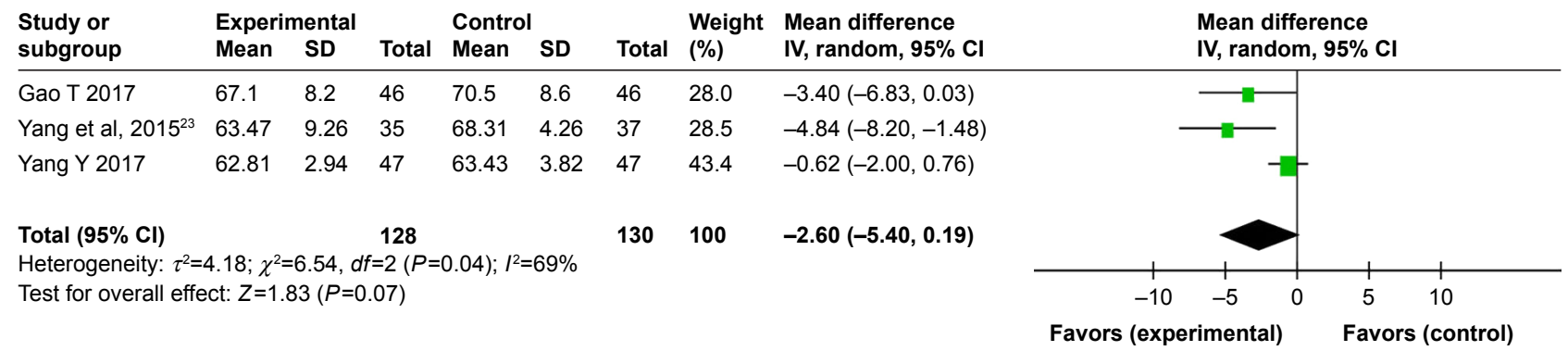

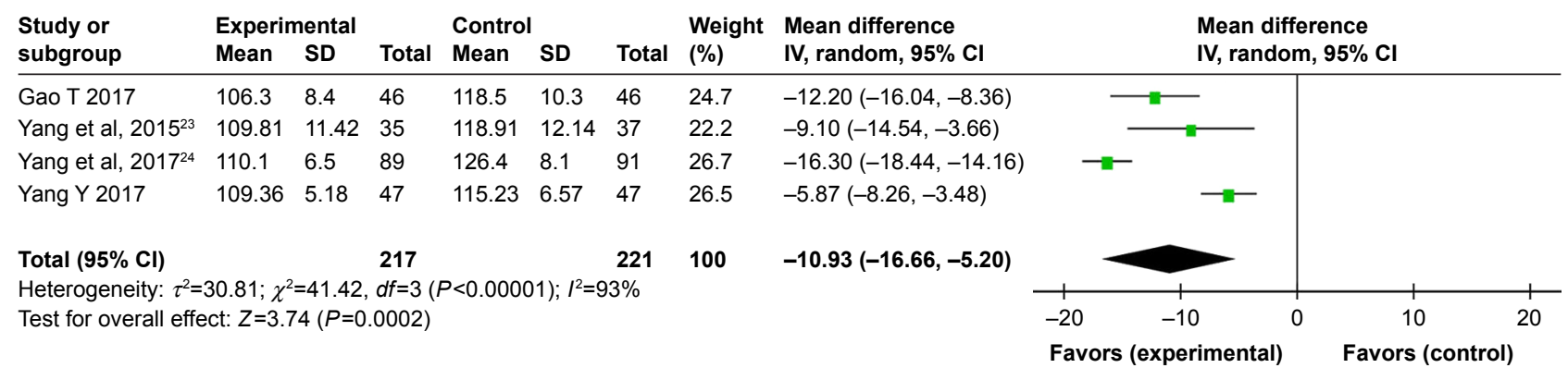

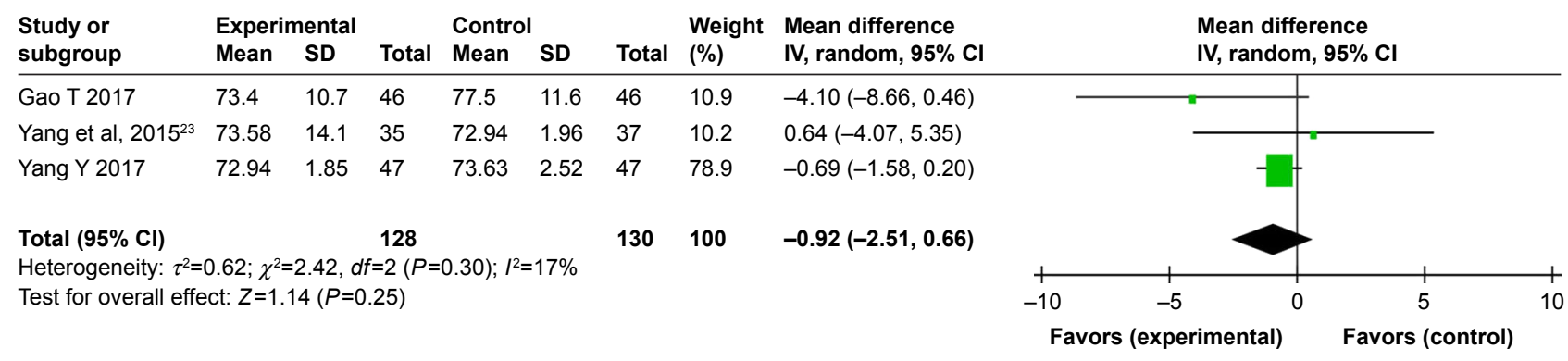

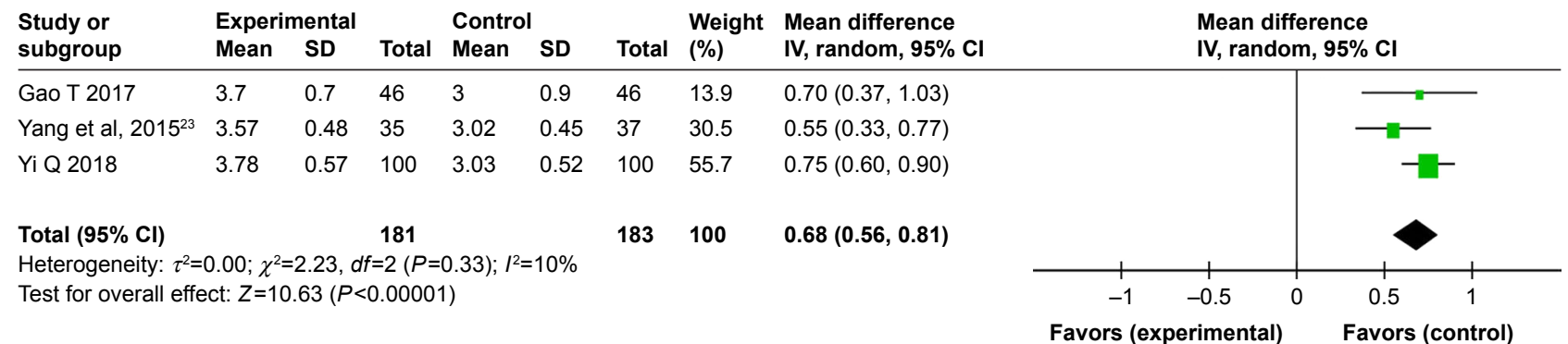

Figure 4 (Continued) 


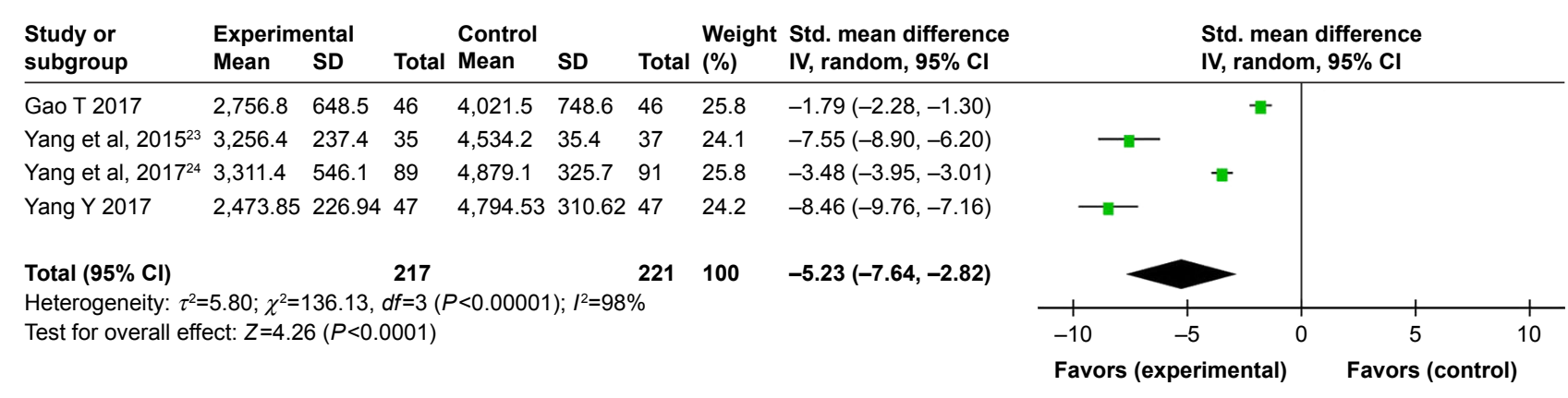

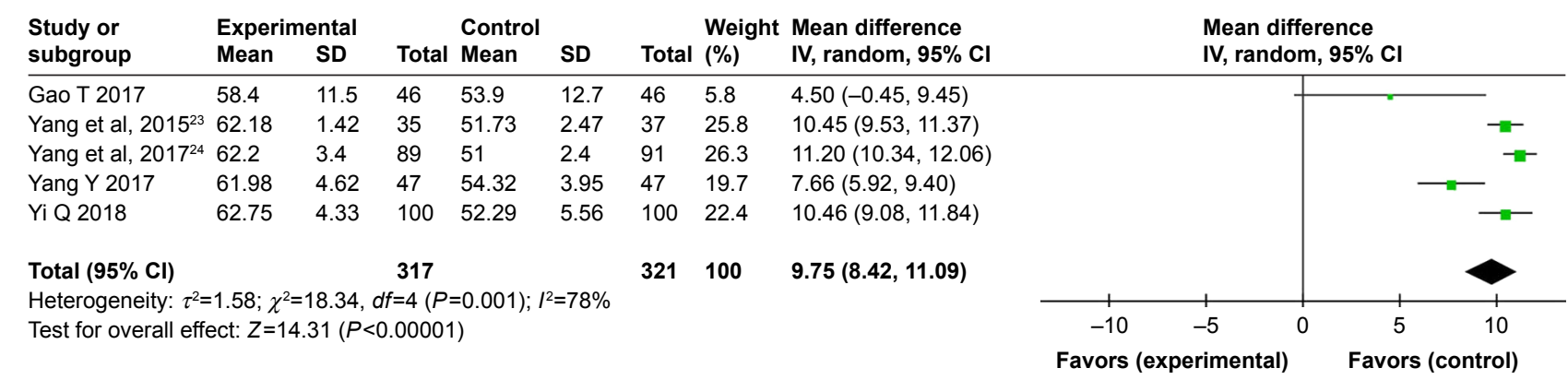

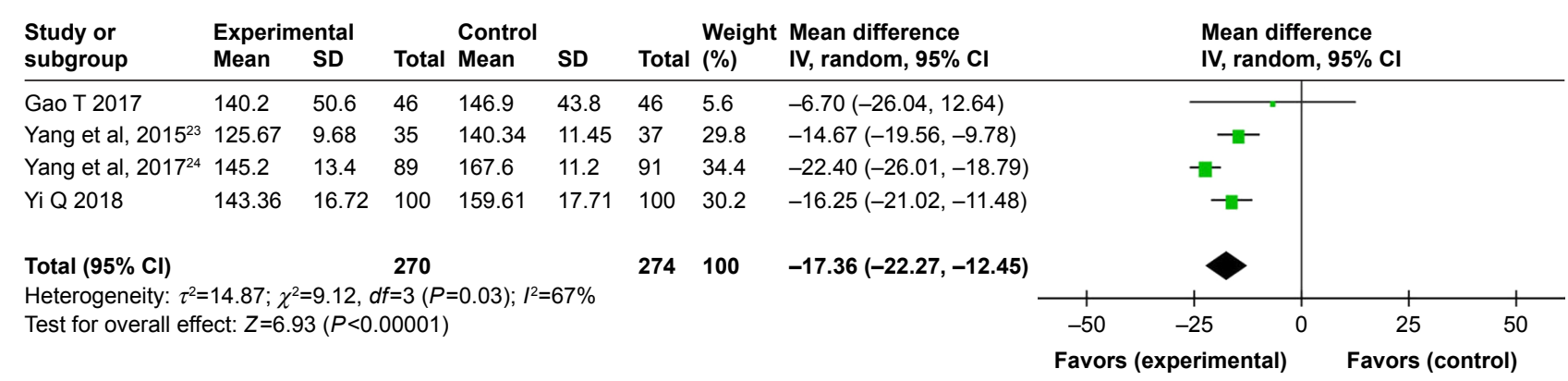

Figure 4 Forest plot diagram showing the DBP, SBP, HR, Cl, NT-proBNP, LVEF and LVEDV.

Abbreviations: $d f$, degrees of freedom; HR, heart rate; LVEDV, left ventricular end-diastolic volume; LVEF, left ventricular ejection fraction; NT-proBNP, N-terminal prohormone of brain natriuretic peptide.

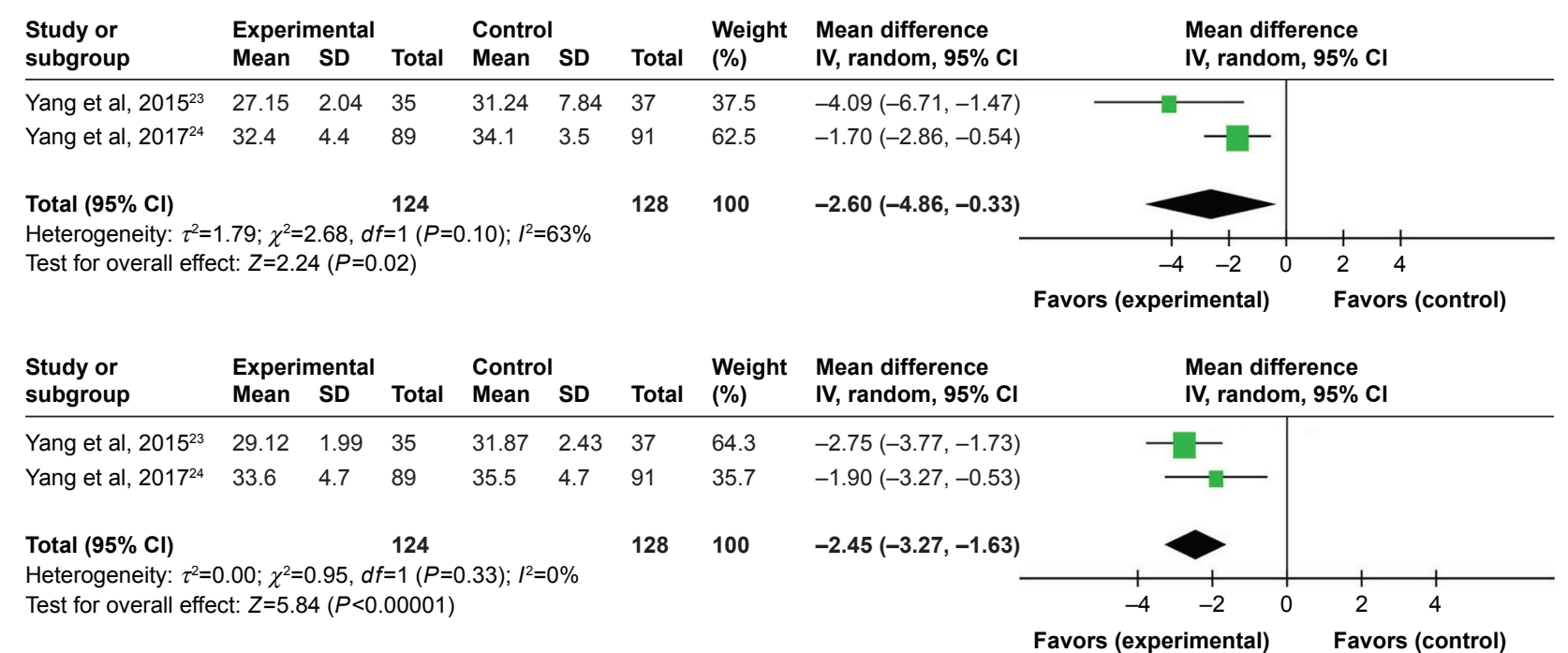

Figure 5 Forest plot diagram showing ALT and AST.

Abbreviation: $d f$, degrees of freedom. 


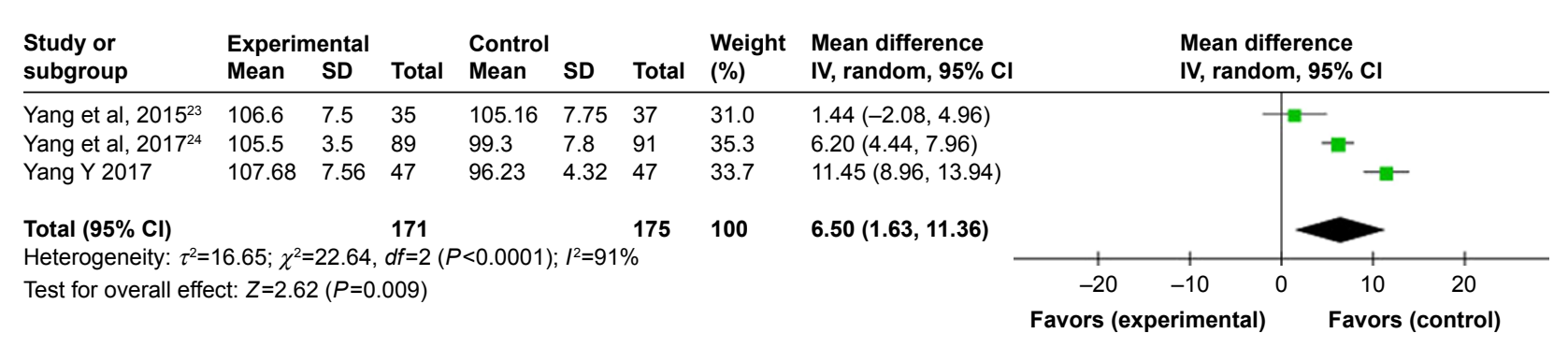

Figure 6 Forest plot diagram showing creatinine.

Abbreviation: $\mathrm{df}$, degrees of freedom.

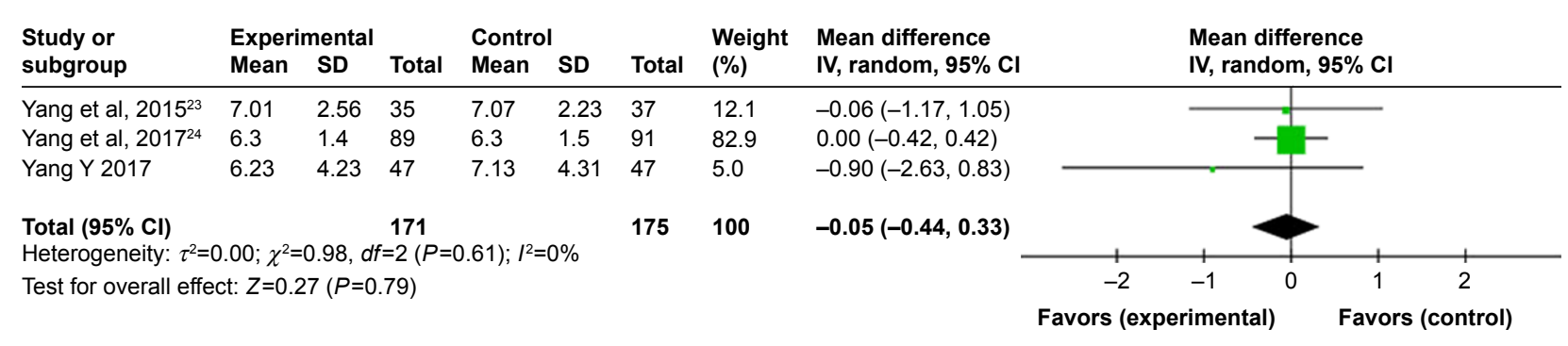

Figure 7 Forest plot diagram showing fasting plasma glucose. Abbreviation: $\mathrm{df}$, degrees of freedom.

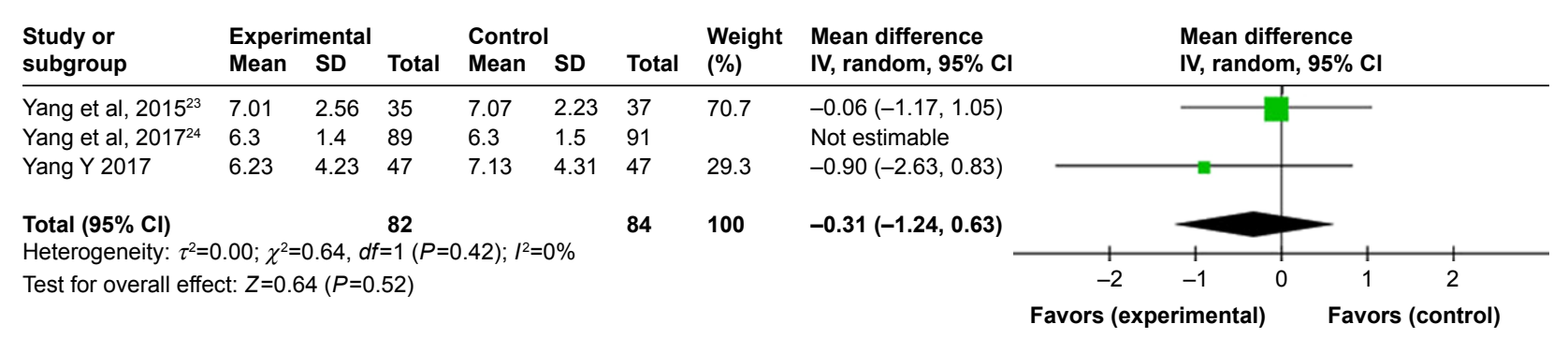

Figure 8 Forest plot diagram showing the fasting plasma glucose of diabetics.

Abbreviation: $\mathrm{df}$, degrees of freedom.

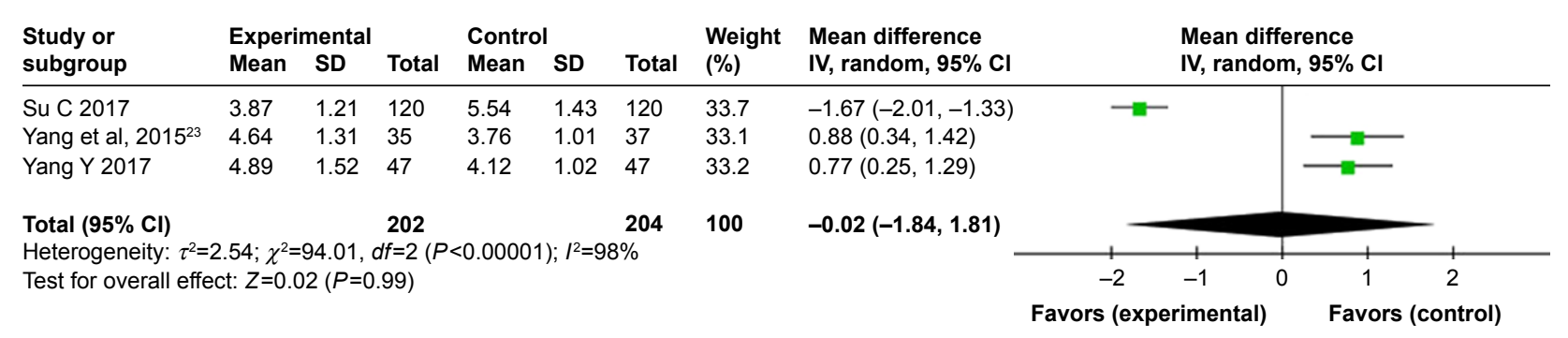

Figure 9 Forest plot diagram showing the total cholesterol.

Abbreviation: $d f$, degrees of freedom.

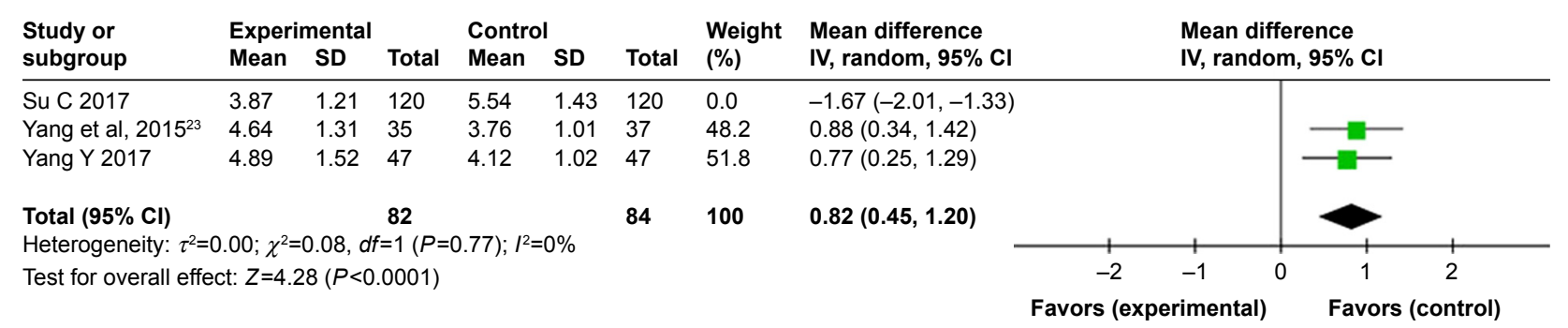

Figure 10 Forest plot diagram showing the total cholesterol of diabetics.

Abbreviation: $d f$, degrees of freedom. 


\begin{tabular}{|c|c|c|c|c|c|}
\hline $\begin{array}{l}\text { Study or } \\
\text { subgroup }\end{array}$ & $\begin{array}{l}\text { Experim } \\
\text { Events }\end{array}$ & $\begin{array}{l}\text { tal } \\
\text { Total }\end{array}$ & $\begin{array}{l}\text { Control } \\
\text { Events }\end{array}$ & Total & $\begin{array}{l}\text { Weight } \\
(\%)\end{array}$ \\
\hline Gao T 2017 & 11 & 46 & 33 & 46 & 42.9 \\
\hline Su C 2017 & 2 & 120 & 5 & 120 & 6.5 \\
\hline Yang et al, $2015^{23}$ & 4 & 35 & 9 & 37 & 11.4 \\
\hline Yang et al, $2017^{24}$ & 1 & 89 & 23 & 91 & 29.5 \\
\hline Yang Y 2017 & 0 & 47 & 7 & 47 & 9.7 \\
\hline Total $(95 \% \mathrm{Cl})$ & & 337 & & 341 & 100 \\
\hline Total events & 18 & & 77 & & \\
\hline \multicolumn{6}{|c|}{ Heterogeneity: $\chi^{2}=6.74, d f=4(P=0.15) ; I^{2}=41 \%$} \\
\hline Test for overall effe & $Z=6.11$ & $<0.0000$ & & & \\
\hline
\end{tabular}

Figure I I Forest plot diagram showing the incidence of complications.

Abbreviations: $d f$, degrees of freedom; M-H, Mantel-Haenszel.

\section{Complications}

The data regarding complications were available in five reports, with a total of 678 patients. A fixed model was used, and slightly significant heterogeneity was observed between the two groups $\left(I^{2}=41 \%, P=0.15\right)$. At the same time, the results showed that the effect of urapidil was better than the effect of nitroglycerin in regard to complications (MD: 0.24, $95 \%$ CI: $0.15,0.38, P<0.00001)$. In addition, we performed a sensitivity analysis of the data. When we deleted the Yang et al (2017) study, ${ }^{24}$ the differences in heterogeneity disappeared and the result was not changed (Figure 11).

\section{Discussion}

Heart failure refers to circulatory dysfunction that is caused by myocardial relaxation or systolic dysfunction. The treatment for heart failure is to reduce the preload and afterload of the heart. ${ }^{25}$ Nitroglycerin regulates calcium channels through the action of nitric oxide (NO), which causes the blood vessels to dilate, ${ }^{26}$ but tolerance to this drug may occur in patients within 24 hours. ${ }^{27}$ However, the mechanism of action of urapidil depends on $\alpha 1$-adrenoceptors and 5-HT receptors. Furthermore, $\alpha$-blockers can also improve the blood lipid profile and glucose metabolism. ${ }^{28}$ To confirm the effectiveness and safety of urapidil, we performed a meta-analysis in order to estimate the effectiveness and safety parameters.

In our analysis, we analyzed the evaluation indicators from two time points. On comparing the LVEF in the experimental group and control group, within 2 days, the experimental group was better than the control group, but the LVEF of both groups reached the normal level (LVEF $>50 \%$ ). However, there was no difference between the two groups in terms of LVESD; therefore, this result was not consistent with the LVEF result between the two groups. Because we knew that the increase in LVEF is necessarily accompanied by a decrease in blood volume after ventricular contraction, the LVESD should be reduced at this time. ${ }^{29} \mathrm{We}$ analyzed and speculated the cause of this phenomenon. First, LVEF parameters had a high heterogeneity, and few studies were included in the analysis, which meant that a sensitivity analysis could not be performed; thus, the final conclusion may be offset. Second, the articles describing LVESD are few in number. If there were enough data, we might have observed an ideal result that is the same as the results found in the trials.

Within 7 days, most of the indicators reflecting the systolic function of the heart revealed the advantages of the experimental group treatment, such as improvements in SBP, NT-proBNP, LVEF, LVEDV and CI. The levels of ALT and AST mainly reflected the function of the liver, and the creatinine levels demonstrated the renal function. Both studies provided data on the toxicity of the drugs and reached the same conclusion, namely, the two drugs were similar in terms of safety. ${ }^{23,24}$ However, through the integrated analysis of the data, we found that urapidil caused less damage to the liver and kidney functions than nitroglycerin. This obviously could not be confirmed by a single experiment. In addition, we also found that urapidil could be used in patients with diabetes, which was confirmed in both in vitro and in vivo experiments..$^{30,31}$

Previous portions of this paper included a discussion of the two drugs, in terms of the treatment effects, after which we analyzed the possible health complications. The elderly AHF patients often have difficulty in tolerating the complications of the drug treatments, especially headache and tachycardia. ${ }^{14}$ This is because urapidil activates the 5-HT receptor and effectively suppresses the sympathetic feedback regulation of the medullary cardiovascular motor center, which is a safer method of action than that of nitroglycerin. ${ }^{32}$ Moreover, urapidil also showed no negative effects in comparison with the readmission rates and mortality rates that were mentioned in the individual experiments. 
At present, animal studies have shown that nonsteroidal anti-inflammatory drugs (NSAIDs) can reduce nitroglycerininduced, NO-mediated brachial vasodilation. ${ }^{33}$ The specific reason is that the NSAIDs are related to the synthesis of thromboxane A2, which regulates vascular homeostasis. ${ }^{34}$ This treatment seemed to ameliorate the side effects of nitroglycerin treatment, but many studies have confirmed that the use of NSAIDs can increase the risk of cardiovascular disease, especially in patients with hypertension, dyslipidemia, diabetes and congestive heart failure. ${ }^{35}$ For the combined use of urapidil and NSAIDs, research has yet to be conducted.

The current research had certain strengths and weaknesses. In terms of strengths, it was the first meta-analysis to compare the use of urapidil with traditional nitroglycerin treatment in hypertensive, elderly patients with AHF. Furthermore, we integrated a small sample of data and discussed the advantage of urapidil treatment, which may help emergency doctors in better managing the disease. Second, our selection of articles was extremely strict, which would reduce the incidence of bias. Third, for the special indicators, we conducted a subgroup analysis. In regard to weaknesses, some of the analyzed clinical studies did not provide statistics; therefore, these data were not included in statistical analyses. Additionally, some experiments had defects in the experimental design, and all of the studies were performed in PR China. The geographic limitations might lead to an ethnic shift. All of these shortcomings might influence some of the reported indexes.

\section{Conclusion}

On analysis of the current evidence, the use of urapidil has been found to improve the LVEF and has no effect on DBP, SBP, LVESD and LVESV in a 2-day time period compared with the use of nitroglycerin. However, the SBP, NT-proBNP, LVEF, LVEDV, CI, ALT, AST and health complications were ameliorated 7 days after urapidil treatment. In addition, the creatinine levels were decreased on treatment with urapidil compared to nitroglycerin. The current quality and quantity of the experiments for this study are both still at a relatively low degree, and all of the present studies originate from Asia. Therefore, more research is needed from other countries in order to avoid the possibility of race deviation, as well as to confirm these results.

\section{Acknowledgments}

The present study was supported by the State Key Program of National Nature Science Foundation of China (grant no 81330042), International Cooperation Program of National
Natural Science Foundation of China (81620108018), National Natural Science Foundation of China (81472070, 81772342 ) and National Natural Science Foundation of China (81702147).

\section{Disclosure}

The authors report no conflicts of interest in this work.

\section{References}

1. Mcmurray JJ, Petrie MC, Murdoch DR, Davie AP. Clinical epidemiology of heart failure: public and private health burden. Eur Heart $J$. 1998;19 Suppl P:P9-P16.

2. Adams KF, Fonarow GC, Emerman CL, et al. Characteristics and outcomes of patients hospitalized for heart failure in the United States: rationale, design, and preliminary observations from the first 100,000 cases in the Acute Decompensated Heart Failure National Registry (ADHERE). Am Heart J. 2005;149(2):209-216.

3. Uchmanowicz I, Jankowska-Polańska B, Mazur G, Sivarajan Froelicher E. Cognitive deficits and self-care behaviors in elderly adults with heart failure. Clin Interv Aging. 2017;12:1565-1572.

4. Wajner A, Zuchinali P, Olsen V, Polanczyk CA, Rohde LE. Causes and predictors of in-hospital mortality in patients admitted with or for heart failure at a tertiary hospital in Brazil. Arq Bras Cardiol. 2017;109(4): 321-330.

5. Horn P, Kelm M, Westenfeld R. Integration of medical therapy and mechanical circulatory support in the management of acute heart failure. Arch Med Sci. 2016;6(6):1317-1323.

6. Alexander P, Alkhawam L, Curry J, et al. Lack of evidence for intravenous vasodilators in ED patients with acute heart failure: a systematic review. Am J Emerg Med. 2015;33(2):133-141.

7. Rudiger A, Harjola VP, Müller A, et al. Acute heart failure: clinical presentation, one-year mortality and prognostic factors. Eur J Heart Fail. 2005;7(4):662-670.

8. Ponikowski P, Voors AA, Anker SD. ESC guidelines for the diagnosis and treatment of acute and chronic heart failure: the Task Force for the diagnosis and treatment of acute and chronic heart failure of the European Society of Cardiology (ESC) developed with the special contribution of the Heart Failure Association (HFA) of the ESC. Eur Heart J. 2016;37(27):2129-2200.

9. Darling CE, Elisabeth Sun J, Goldberg J, et al. A historical perspective on presentations of hypertensive acute heart failure. $J$ Cardiovasc Dis Diagn. 2017;05(03):2329-9517.

10. Levy PD, Laribi S, Mebazaa A. Vasodilators in acute heart failure: review of the latest studies. Curr Emerg Hosp Med Rep. 2014;2(2) 126-132.

11. Hunter BR, Martindale J, Abdel-Hafez O, Pang PS. Approach to acute heart failure in the emergency department. Prog Cardiovasc Dis. 2017; 60(2):178-186.

12. Viau DM, Sala-Mercado JA, Spranger MD, O'Leary DS, Levy PD. The pathophysiology of hypertensive acute heart failure. Heart. 2015; 101(23):1861-1867.

13. Writing Committee Members; Yancy CW, Jessup M, et al. 2013 ACCF/ AHA guideline for the management of heart failure: a report of the American College of Cardiology Foundation/American Heart Association Task Force on practice guidelines. Circulation. 2013;128(16): e240-e327.

14. den Uil CA, Brugts JJ. Impact of intravenous nitroglycerin in the management of acute decompensated heart failure. Curr Heart Fail Rep. 2015;12(1):87-93

15. Elkayam U, Bitar F, Akhter MW, Khan S, Patrus S, Derakhshani M. Intravenous nitroglycerin in the treatment of decompensated heart failure: potential benefits and limitations. J Cardiovasc Pharmacol Ther. 2004;9(4):227-241. 
16. Saxena PR, Villalón CM. Brain 5-HT1A receptor agonism: a novel mechanism for antihypertensive action. Trends Pharmacol Sci. 1990; 11(3):95-96.

17. Bopp C, Auger C, Diemunsch P, Schini-Kerth V. The effect of urapidil, an alpha-1 adrenoceptor antagonist and a 5-HT1A agonist, on the vascular tone of the porcine coronary and pulmonary arteries, the rat aorta and the human pulmonary artery. Eur J Pharmacol. 2016;779:53-58.

18. Gross G, Hanft G, Rugevics C. 5-Methyl-urapidil discriminates between subtypes of the alpha 1-adrenoceptor. Eur J Pharmacol. 1988;151(2): 333-335.

19. van Zwieten PA, Bruning TA. Comparison of the hemodynamic effects of urapidil and flesinoxan in healthy volunteers. Blood Press Suppl. 1994;4:19-24.

20. Alijotas-Reig J, Bove-Farre I, de Cabo-Frances F, Angles-Coll R. Effectiveness and safety of prehospital urapidil for hypertensive emergencies. Am J Emerg Med. 2001;19(2):130-133.

21. Hirschl MM, Binder M, Bur A, et al. Safety and efficacy of urapidil and sodium nitroprusside in the treatment of hypertensive emergencies. Intensive Care Med. 1997;23(8):885-888.

22. Shi J, Li A, Wei Z, et al. Ketamine versus ketamine pluses atropine for pediatric sedation: a meta-analysis. Am JEmerg Med. 2018;36(7):1280-1286.

23. Yang W, Zhou YJ, Fu Y, et al. A multicenter, randomized, trial comparing urapidil and nitroglycerin in multifactor heart failure in the elderly. Am J Med Sci. 2015;350(2):109-115.

24. Yang W, Zhou YJ, Fu Y, et al. Efficacy and safety of intravenous urapidil for older hypertensive patients with acute heart failure: a multicenter randomized controlled trial. Yonsei Med J. 2017;58(1):105-113.

25. Elkayam U, Janmohamed M, Habib M, Hatamizadeh P. Vasodilators in the management of acute heart failure. Crit Care Med. 2008; 36(1 Suppl):S95-S105.

26. Fung HL. Pharmacokinetic determinants of nitrate action. Am J Med. $1984 ; 76(6 \mathrm{~A}): 22-26$.
27. Elkayam U, Kulick D, Mcintosh N, Roth A, Hsueh W, Rahimtoola SH. Incidence of early tolerance to hemodynamic effects of continuous infusion of nitroglycerin in patients with coronary artery disease and heart failure. Circulation. 1987;76(3):577-584.

28. Buch J. Urapidil, a dual-acting antihypertensive agent: current usage considerations. Adv Ther. 2010;27(7):426-443.

29. Vermeiren GL, Malbrain ML, Walpot JM. Cardiac ultrasonography in the critical care setting: a practical approach to assess cardiac function and preload for the "non-cardiologist". Anestezjol Intens Ter. 2015; 47(Spec No):s89-s104.

30. Oren S, Turkot S, Paran E, Flandra O, Slezak L, Hof B. Efficacy and tolerability of slow release urapidil (ebrantil) in hypertensive patients with non-insulin dependent diabetes mellitus (NIDDM). J Hum Hypertens. 1996;10(2):123-127.

31. Ittner KP, Zimmermann M, Bucher M, et al. The effect of urapidil and ramipril on hyperglycemia in streptozotocin diabetic rats. Naunyn Schmiedebergs Arch Pharmacol. 2000;361(1):92-97.

32. Ramage AG. The mechanism of the sympathoinhibitory action of urapidil: role of 5-HT1A receptors. Br J Pharmacol. 1991;102(4): 998-1002.

33. Li H, Hortmann M, Daiber A, et al. Cyclooxygenase 2-selective and nonselective nonsteroidal anti-inflammatory drugs induce oxidative stress by up-regulating vascular NADPH oxidases. J Pharmacol Exp Ther. 2008;326(3):745-753.

34. Seo KW, Park JS, Tahk SJ, Shin JH. A case of acute myocardial infarction induced by selective cyclooxygenase-2 inhibitor. Chin Med J. 2017;130(9):1131-1132.

35. Huang WF, Hsiao FY, Wen YW, Tsai YW. Cardiovascular events associated with the use of four nonselective NSAIDs (etodolac, nabumetone, ibuprofen, or naproxen) versus a cyclooxygenase-2 inhibitor (celecoxib): a population-based analysis in Taiwanese adults. Clin Ther. 2006; 28(11):1827-1836.
Drug Design, Development and Therapy

\section{Publish your work in this journal}

Drug Design, Development and Therapy is an international, peerreviewed open-access journal that spans the spectrum of drug design and development through to clinical applications. Clinical outcomes, patient safety, and programs for the development and effective, safe, and sustained use of medicines are the features of the journal, which

\section{Dovepress}

has also been accepted for indexing on PubMed Central. The manuscript management system is completely online and includes a very quick and fair peer-review system, which is all easy to use. Visit http://www.dovepress.com/testimonials.php to read real quotes from published authors. 